\title{
Att höra röster: Tre faser av lyssnande ${ }^{1}$
}

\author{
SIMON STJERNHOLM
}

\begin{abstract}
ENGLISH ABSTRACT: This article describes and discusses an ongoing attempt to listen better to the meaning-making potential that is not only inherent in words, but also in human speech's auditory dimensions. Through a presentation of three chronologically ordered phases of listening, with particular focus on various forms of Muslim preaching, a string of fruitful analytical paths for aurally oriented studies of religion are expounded. The empirical examples include listening practices within a contemporary Sufi order, digitally disseminated oral Islamist messages, and media-adapted Muslim preaching with varying ideological content and communicative strategies. The article also relates these examples and analyses to a wider research field within the study of religion with attention to sound and voices.
\end{abstract}

SVENSK RESUME: Denna artikel beskriver och diskuterar en pågående strävan efter att lyssna bättre till den meningsbärande potential som inte enbart ryms $i$ ord, utan även $i$ det mänskliga talets auditiva dimensioner. Genom en presentation av tre kronologiskt ordnade faser av lyssnande, med särskilt fokus på olika former av muslimsk predikan, utläggs en rad fruktbara analytiska spår för auditivt orienterad religionsforskning. De empiriska exemplen inkluderar lyssningspraktiker inom en nutida sufiorden, digitalt förmedlade muntliga islamistiska budskap, samt medieanpassad muslimsk predikan med varierande ideologiskt innehåll och kommunikativa strategier. Artikeln relaterar även exemplen och analyserna till ett bredare religionsvetenskapligt forskningsfält med uppmärksamhet mot ljud och röster.

KEY WORDS: Röster; ljud; predikan; islam; kommunikation.

Som religionsforskare är listan över möjliga relevanta typer av material att analysera nästintill oändlig. Som effekt av en serie 'vändningar' inom religionsforskning och humanistisk forskning i bredare bemärkelse - till exempel vad som kallats den 'materiella vändningen' och den 'visuella vändningen' - har det blivit vanligt att forskare

1 Delar av denna artikels innehåll har presenterats vid DASR/RvT-seminariet om "Religion och medier" vid Aarhus universitet i december 2018, samt vid en workshop i maj 2019 på temat "How does data shape our analysis?" arrangerad av ett interdisciplinärt forskningskluster med fokus på religion vid Institut for Tvärkulturella och Regionala Studier, Köpenhamns universitet. Jag är tacksam för de konstruktiva kommentarer deltagarna i respektive arrangemang har bidragit med. Särskilt tack riktas till Andreas Bandak för goda samtal och litteraturtips. 
fokuserar på andra typer av källor än skrivna texter, vilka under många år annars dominerade religionsvetenskapen. Detta har på många sätt berikat religionsforskningen, då många forskare kommit att undersöka en mångfald av religiösa uttryck och handlingar, sociala arenor, kommunikationsformer, semiotiska ideologier och mycket annat som tidigare ofta negligerats.

I denna artikel reflekterar jag över min egen gradvisa process mot en mer komplex förståelse av - och analytiskt engagemang med - icke-textuella aspekter av auditivt empiriskt material. Särskilt fokus har artikeln på betydelsen av mänskliga röster som ljud. Att uppmärksamma rösters auditiva aspekter i religiösa sammanhang kan möjliggöra fler tolkningsmöjligheter än en analys som endast sysselsätter sig med orden som kommuniceras - som om tal var entydigt med skrift. Artikeln spårar därför kronologiskt, med utgångspunkt i tre olika faser av lyssnande, ett gradvis ökande intresse för skillnaden mellan att lyssna till röster och att läsa texter. Målet är att därigenom peka ut analytiska impulser och möjligheter av både specifik och mer generell karaktär. Den första fasen sammanfaller med min tid som forskarstuderande, då jag arbetade på en avhandling om en nutida sufiorden, Naqshbandi-Haqqani. ${ }^{2}$ Här fokuserar jag på lyssningspraktiker rörande ordens ledande shaykh och hur mina förväntningar blev utmanade av shaykhens följares sätt att relatera till hans muntliga kommunikation. Fas två relaterar till ett forskningsprojekt jag utförde åt en svensk myndighet med syfte att kartlägga och analysera våldsbejakande islamistiska budskap på internet. Under detta arbete kom de auditiva och multimodala aspekterna av ljud- och video-filer att framstå som viktiga för hur de kunde uppfattas av olika publikgrupper. I den tredje fasen, som är pågående, har uppmärksamheten varit mer avgränsad till olika former av muslimsk predikan i Sverige. Arbetet med olika mediegenrer har visat att röstens användning anpassas till det mediala och diskursiva sammanhanget. Sammantaget illustrerar de tre faserna av lyssnande alla på sitt vis att den meningsskapande potentialen för mänskligt tal inte uttöms av dess ord: den auditiva dimensionen tillför något som potentiellt är av vikt.

En jämförbar behandling av hur ljud successivt blev allt mer centralt i en analytisk process finns i Andreas Bandaks (2014) reflektion över sitt fältarbete bland kristna i Damaskus. Bandak beskriver en process genom vilken de offentliga ljuden i staden såsom musikinstrument, kyrkklockor och böneutrop från moskéer - gradvis kom att uppmärksammas mer i analysen, med särskilt fokus på ljudet av de kristna grupper han studerade. Den process jag här beskriver är mer specifikt fokuserad på mänskliga röster som de används i olika former av muslimsk predikan. Samtidigt relateras detta specifika intresseområde till ett bredare forskningsfält rörande ljud och röster i forskning om religiositet.

2 Andra namn för denna orden är också i bruk, däribland Naqshbandiyya-Nazimiyya. Jag har dock valt att behålla den benämning som var dominerande vid tiden för mitt huvudsakliga arbete med orden. 


\section{Ljud, röster och religionsforskning}

Titeln på denna artikel anspelar på religionshistorikern Leigh Eric Schmidts banbrytande arbete om religion och ljud, Hearing Things: Religion, Evolution, and the American Enlightenment (2000). Schmidt undersökte där hur upplevelser av ljud - särskilt ljud som påstods ha ett övernaturligt ursprung - både ofta blev misstänkliggjort och gjort bruk av i religiös och vetenskaplig argumentation under den amerikanska upplysningstiden. Sedan Schmidts bok publicerades för tjugo år sedan, har en rad forskare undersökt 'religiösa' ljud, inklusive röster, i olika kulturella och historiska kontexter (se t.ex. Weiner 2011; Hackett 2011, 2017). Forskningsfältet 'religion och ljud' relaterar samtidigt också till ett bredare forskningsfält med fokus på ljud och auditiv kultur (för introduktioner till detta fält, se Sterne 2012; Bull and Back 2016).

Redan på 1970-talet hade fenomenologen Don Ihde (2007 [1976]) skrivit om hur upplevelsen av ljud särskiljer sig från andra erfarenheter. Ihde poängterade bland annat att: "to listen and to understand mean more than the comprehension of words, they signify entry into a wider communication situation" $(2007,152)$. I denna artikel beskrivs och diskuteras en pågående strävan efter att lyssna bättre till den meningsbärande potential som inte enbart ryms i orden, utan även i talets auditiva dimensioner. Syftet är därmed inte alls att förvägra en central roll till det konventionella språkets system av ord och dess referenter, utan snarare att uppmärksamma den vidare kommunikativa kontext som talade ord alltid är en del av. Ord, yttrade som tal, är kommunikativt sett aldrig 'bara ord'; röster är inte neutrala bärare av ordens inneboende data. Bland möjliga infallsvinklar att beakta är vad Ihde kallar rösters 'musikaliska' aspekt, eftersom mening kan finnas "in the sounding" (2007, 158). En ytterligare aspekt hos Ihde är relationen mellan det sagda och det osagda, eller "the unspoken context which surrounds speech" $(2007,166)$. Denna outtalade kontext relaterar specifika uttalanden till en gruppgemenskap och en historia, vilka Ihde menar att lyssnaren kan träda in i genom att lära sig höra det osagda. En tystnad kan ibland vara talande, liksom tonfallet hos en talare kan signalera att ord yttras med ironi eller förakt - något som inte nödvändigtvis framgår av orden själva. Likaså har talets kulturella och sociala inramning betydelse för dess betydelse och lämplighet.

En forskare som arbetat med den bredare kontexten för ljud och dess effekter, är antropologen Charles Hirschkind, vars bok The Ethical Soundscape: Cassette Sermons and Islamic Counterpublics (2006) fokuserade på kassettpredikningar i Kairo - dess kontext, produktion, innehåll och bruk. Boken har blivit en ofta återkommande referens för forskare inom olika discipliner som på något sätt arbetar med ljud. Hirschkind använder begreppet soundscape för att tala om den auditiva inbäddning som predikningar är en del av - och som påverkar hur de uppfattas. Kassettpredikningar är för honom mer än en teknologi för etisk självformering. De inlemmas i ett fromt soundscape som även innehåller till exempel högtalarförstärkt kallelse till bön (adhan) samt uppspelning av koranrecitation och predikningar i offentliga miljöer. Detta soundscape producerar "an environment wherein certain styles of speech and comportment become marked as inappropriate" (s. 124). En viss sammansatt auditiv miljö kan sammankopplas med "a particular form of life, and its repertoires of postural, 
gestural, and effective expression" (s. 125). Hirschkind analyserar även hur enskilda kassettpredikningar låter och upplevs av dess lyssnare.

I sina studier av muslimers bruk av en mångfald medier i Mali har antropologen Dorothea Schulz (2012a. 2012b. 2012c. 2015) poängterat de dynamiker genom vilka olika röster uppfattas av en bestämd publik. Schulz noterar bland annat att kvinnliga radiopredikanter blev hörda på ett annat sätt än manliga predikanter, beroende på kulturellt formade sätt att uppfatta olika röster i offentligheten. Detta hade både att göra med konstruktioner av könsroller, men också med konstruktioner av rösten som medium: vad rösten på acceptabelt vis kunde användas till, av vem, samt var och när. En annan givande studie av hur röster tillskrivs mening är Jonathan Sternes (2008) analys av hur Osama bin Ladins röst behandlats som 'fienderöst' i amerikanska medier; den behandlades som kvalitativt annorlunda än mainstream-politikers röster, hackades upp och omgavs med en 'diskursiv slöja', som om bin Ladins röst $i$ sig själv förväntades ha ett visst inflytande på lyssnaren oberoende av hans ord. Detta bidrog till ett medialt och politiskt "project of rendering the enemy alien, exotic, and hateful" (s. 86); bin Ladins röst konstruerades därigenom som ett annat slags röst än andra politiska aktivisters röster.

Kulturella variationer gällande hur materiell kultur tillskrivs egenskaper, betydelser och bruksmöjligheter - härunder sinnesperceptioner och -erfarenheter såsom upplevelser av röster - kan förstås som representerande olika semiotiska ideologier (Meyer 2011; se också Engelke 2007; Keane 2008). Det innebär att vad en grupp av människor uppfattar som 'inget särskilt' eller kanske till och med 'nonsens', kan för en annan grupp vara exempelvis 'heligt' eller 'farligt'. Matthew Engelkes (2007) studie av en grupp kristna i Zimbabwe som prioriterar 'live and direct' tal framför Bibeln som bok - vilken därför kan behandlas på sätt som många andra kristna skulle finna vanvördiga - är ett exempel. De fenomen som tillskrivs semiotiska kvaliteter inkluderar sinnliga erfarenheter, såsom att höra musik eller röster. Isaac Weiner (2014) har genom att studera rättsfall i deras historiska sammanhang undersökt hur ljudet av religiositet på olika vis har aktualiserat juridiska, politiska och identitetsmässiga problemkomplex, inklusive en gradvis omförhandling av hur det amerikanska rättssystemet har definierat 'religion'. En nyligen utförd studie av hur lokalpolitiker hanterat religiöst ljud från kyrkor respektive moskéer i dansk kontext sätter fokus på liknande problemställningar (Jacobsen, Daverkosen \& Larsen 2019). Weiner är också en av de drivande bakom American Religious Sounds Project (ARSP), ${ }^{3}$ som utöver att arrangera workshops och föra samman forskare med intresse för religiösa ljud även har producerat ett sökbart online-ljudarkiv och en rad därtill relaterade undervisningstips för att underlätta integration av ljud i religionsvetenskaplig undervisning.

En användbar konceptualisering av samexistensen av kommunikationssätt (communicative modes) är multimodalitet. För Gunther Kress (2010), en av de centrala tänkarna gällande multimodalitet och socialsemiotik, är en viktig poäng att flera kommunikationssätt interagerar i den meningsskapande processen. Skrift är inte nödvändigtvis det mest dominerande eller viktigaste kommunikationssättet att beakta i en 
humanvetenskaplig analys. Varje kommunikationssätt har sina inneboende egenskaper (affordances), dess möjligheter och begränsningar. Kommunikationssättet tal innehåller ord som är meningsbärande, men kan även inkludera intonation, tystnad, skiften mellan olika språk, dialekter och andra aspekter vilka bidrar till lyssnarens meningsskapande process.

Genom läsning av bland annat den litteratur som nämnts här har min uppmärksamhet gradvis kommit att riktas mot att komplettera analys av språk-som-ord med andra, samexisterande, kommunikationssätt. Ett av de för mig mer intressanta är den mänskliga rösten och dess varierande användning. I följande avsnitt kommer jag att gå igenom tre distinkta faser av lyssnande i min egen forskningsutveckling. Varje fas illustrerar specifika rörelser bort från ett exklusivt fokus på ord som betydelsefulla i religionsvetenskapliga analyser.

\section{Tre faser av lyssnande}

De tre faserna är kronologiskt ordnade och inleds med mitt arbete som forskarstudent för att avslutas med mitt senaste arbete. Utvecklingslinjen ska dock ses som pågående snarare än avslutad; jag har inte för avsikt att formulera några slutgiltiga slutsatser utan snarare peka på metodologiska och analytiska öppningar. Denna artikel sätter därmed ord på ett gradvis öppnande av nya frågor och forskningsmaterial.

\section{Mästarens röst}

Den första fasen av lyssnande inföll under arbetet med min doktorsavhandling (Stjernholm 2011), i vilken jag undersökte aktiviteter och narrativ bland deltagare i den transnationella muslimska sufi-orden Naqshbandi-Haqqani. Särskilt fokus riktade avhandlingen mot ett center i London samt ordens ledande shaykhs hem på norra Cypern. Under mitt materialinsamlande spenderade jag ett otal timmar med att lyssna till röster: i konversationer med människor jag mötte, i intervjuer, i undervisningssituationer där en grupp diskuterade religiösa frågor tillsammans, framför videoinspelningar av shaykhens tal som distribuerades på DVD eller via internet, och sittande på moskégolv lyssnande till en predikan. I följande avsnitt fokuserar jag specifikt på den muntliga kommunikationen från ordens andliga ledare, Shaykh Muhammad Nazim Adil al-Haqqani al-Qubrusi (1922-2014), som tillskrevs en oerhört central roll i denna religiösa gemenskap. Shaykh Nazim var av turkcypriotisk familjebakgrund, men var sedan 1970-talet känd över hela världen som en av de sufimuslimska andliga ledare som hade mest framgång med att vinna anhängare för sitt budskap i ickemuslimskt dominerade samhällen (för forskning om denna orden, se t.ex. Geaves 2000; Nielsen, Draper \& Yemelianova 2006; Damrel 2006; Atay 2012; Stjernholm 2014, 2015).

Jag lyssnade till shaykhens ord - samt orden från hans högt rankade företrädare - i olika miljöer. En sådan miljö var sittande på golvet till den lilla moské som var sammanbyggd med hans hus på Cypern, medan shaykhen talade från sin stol framför moskéns mihrab. Jag lyssnade även till honom många timmar i mitt källarkontor i 
Lund, från DVD-skivor och internetplattformar som YouTube. Den typen av inspelningar lyssnade jag även till i London tillsammans med shaykhens andliga lärjungar, i suficentret eller i privata hem. Det var tydligt att distribution och lyssnande till dessa tal (sing. sohbet) av andliga mästare, i synnerhet Shaykh Nazim själv, sågs som en central dimension av gruppens religiösa liv. Orden från shaykhen och hans främsta företrädare blev även samlade, redigerade och utgivna som böcker.

Syftet med mitt lyssnande som ung forskarstuderande var som utgångspunkt att förstå budskapet som kommunicerades genom ord. Man kan säga att jag närmade mig dessa lyssningstillfällen med en textuell partiskhet. Vad som spelade mest roll, tog jag för givet i projektets tidiga fas, var det diskursiva innehåll som förmedlades; idéerna, berättelserna och informationen som talaren önskade överföra till publiken - eller publiken önskade utvinna ur talaren. Jag ville gärna förstå vad talaren sade eftersom det, ur mitt perspektiv, borde vara det viktigaste för de shaykhens följare som jag mötte och samtalade med.

Utan tvivel var shaykhens ord viktiga. De diskuterades ofta efter en lyssningssession. När Shaykh Nazim exempelvis hade talat om hur man kunde öka sin nivå av andlighet, eller efter att ha beskrivit världens ände och tecknen på dess nalkande (vilket han återkom till många gånger genom åren), blev dessa ämnen ofta intensivt tolkade och diskuterade bland gruppens deltagare. Det kan förefalla självklart och därmed oproblematiskt. Men samtidigt var det några faktorer som gjorde bilden mer komplex. En sådan faktor var redundans. Enkelt uttryckt blev långt mycket mer tal distribuerat i olika former än vad som strängt talat var 'nödvändigt' för att kommunicera ett visst budskap; kanske till och med mer än vad som var möjligt att ta in (åtminstone för mig). Shaykh Nazim upprepade också liknande budskap om och om igen. Detta indikerar att lyssnandets betydelse inte enbart var att förstå och reflektera över varje ord han yttrade; dess meningsskapande potential var inte begränsade till det diskursiva innehållet i orden som framsades. Här kan en parallell ses till kapitlet om 'dödens akustik' i Hirschkinds ovan refererade bok The Ethical Soundscape, där han kommenterar den centrala plats som beskrivelser av och tankar på döden upptar för de predikanter han lyssnar till. Snarare än att vara uttryck för en morbid inställning till livet, menar Hirschkind att predikanterna - och deras lyssnare - strävar efter att leva livet i konstant medvetenhet om dödens realitet och oundviklighet. Genom att lyssna på ständiga påminnelser om döden och forma sitt beteende - sitt själv - efter detta, kan dödsmedvetenheten inkorporeras till dess att "the knowledge of death becomes the principle of all action" (s. 188). Framtiden (den individuella döden och eskatologiska visioner) blir därmed närvarande i och konstituerande av nuet. På jämförbart sätt kan Shaykh Nazims följare sägas göra sig själva medvetna om, eller fokuserade på, shaykhens vägledning i det närmaste konstant genom att lyssna till hans ord, vilket ofta sker i kombination med att se på bilder av honom, läsa böcker innehållande hans ord, och frammana bilden och ljudet av honom i minnet, något som $\mathrm{i}$ Naqsbandiyya-traditionen är känt som rabita, att binda sitt hjärta till mästaren (se t.ex. Weismann 2007, 89f). En sufishaykhs vägledning föreställs i sufitraditionen vara fullständigt avgörande för att uppnå andliga framsteg. Att låta sinnena påverkas så mycket som möjligt av shaykhen auditivt och visuellt är ett sätt att öppna upp sig 
själv för andliga framsteg. Då kan metoden fungera även om det är i stort sett samma tal som lyssnas till återkommande, eller samma bild av shaykhen som betraktas dagligen. Det är det sinnliga intryckets effekt på självet - som gudomlig välsignelse (baraka) och som andlig övning - som eftersträvas snarare än, eller som komplement till, rationellt orienterad kunskapsinhämtning.

Ytterligare en faktor hade att göra med Shaykh Nazims stigande ålder. I takt med hans högre ålder ändrades hans sätt att tala, men värdet som tillskrevs hans tal ändrades inte på motsvarande sätt. Shaykh Nazim hade enligt sina följare under många år en mycket kraftfull och överväldigande personlighet, både fysiskt, visuellt och verbalt. Under hans sista år i livet var han dock, helt rimligt, fysiskt svagare än tidigare (shaykhen dog 2014 vid en ålder av 92 år). Vidare hade han under många år framgångsfullt använt det engelska språket för att attrahera följare globalt (samtidigt som han var flytande på turkiska och arabiska). Men med högre ålder verkade han behöva kämpa för att finna de rätta orden, formulera sammanhängande meningar och hålla fokus på att genomföra ett argument eller slutföra en berättelse. Hans offentligt framförda tal blev därför, ur mitt perspektiv, svårare att följa och mer utmanande att förstå. Mot slutet av shaykhens liv måste jag erkänna att jag hade svårt att hänga med i och få grepp om hans muntliga kommunikation.

Samtidigt verkade shaykhens tal under denna sena period av hans liv inte tillskrivas mindre betydelse; möjligen snarare mer. Då shaykhens tal blev mindre förståeligt för mig, föreföll det inte alls uppfattas som mindre värt bland hans följare. Auktoriteten som tillskrevs Shaykh Nazim hade inte enbart att göra med honom som individ utan i hög grad också med vad han representerade och förkroppsligade. I traditionell sufimuslimsk konceptualisering av den grupp av människor som kallas awliya Allah, 'gudsvänner' (ofta översatt till 'helgon'), är en nyckelaspekt dessa personers interaktion med icke-fysiska dimensioner och verkligheter. En stor mängd budskap, visioner och instruktioner rapporteras ha kommit till dessa awliya genom deras kommunikation med avlidna profeter och äldre tiders gudsvänner som utmärks av deras närhet till Gud i en andlig värld (om awliya i sufitraditionen, se t.ex. Abun-Nasr 2007).

Att höra shaykhen tala innebar därför för hans hängivna följare att samtidigt höra annat-än-honom eller mer-än-honom. Hans tal var för dem inte reducerbart till ord och dess referenter; shaykhens tal var samtidigt en mediering av närhet till Gud och kontakt med en idealiserad andlig värld. Om shaykhens följare perfekt kunde förstå betydelsen av vad han hade sagt i ett givet tal, var det utmärkt. Men samtidigt: om de hade svårt att greppa den precisa innebörden i vad han sagt, eller om det rentav gick dem fullständigt förbi - så var det också acceptabelt, eftersom de ändå fick del av välsignande baraka genom att ha hört shaykhen tala. Hans röst och närvaro signalerade närvaron av gudomlig kontakt och legitimiteten i en lång tradition av gudsvänner med en särskilt hög andlig nivå.

Förtjänsten av att lyssna kunde för dessa sufimuslimer därför inte helt likställas med förståelse. Utöver att förstå var också oerhört viktigt att höra honom, inte endast för att förstå den diskursiva innebörden av vad som sades. Att visa uppmärksamhet åt rösten till den som hävdades vara den högsta andliga auktoriteten på jorden föreställdes vara gynnsamt för lyssnaren eftersom det var ett medium för kontakt - inte 
enbart med ideal och narrativ, utan med en tänkt andlig värld som förväntades ha stor inverkan på de som upplevde den.

\section{Extremistiska röster}

En senare fas av religionsvetenskapligt lyssnande till röster inföll då jag arbetade med en forskningsrapport åt den svenska statliga myndigheten Statens medieråd på uppdrag av Sveriges regering. Mitt uppdrag var att kartlägga och analysera våldsbejakande islamistiska budskap på den svenskspråkiga webben. Arbetet innebar hantering och analys av olika typer av data, inklusive skrivna artiklar, hemsidor med frågor-och-svar, stillbilder, videor och innehåll från sociala medier. Materialtyper som blev centrala för min undersökning var bland annat två former av inspelat tal: å ena sidan föreläsningar i relativt fritt format, å andra sidan korta redigerade bitar av religiösa tal som kombinerats med bilder till vad jag kallar 'påminnelser'. Dessa påminnelser byggde ofta på en speciellt intensiv del av en föreläsning eller predikan, då talaren nådde ett slags klimax. I en studie som delvis berör liknande arabiskt material, har Hirschkind (2012) noterat den 'rörande' (mu'aththir) effekt som dessa korta videoklipp sägs ha på publiken. De förväntas alltså kunna emotionellt röra eller påverka en person i from riktning (Stjernholm 2020).

Ofta uttrycktes intensiteten genom att rösten var i en hög frekvens, ibland nästintill skrikande, samt ibland gråtande i ett performativt uttryck av känslomässig intensitet och smärta över världens tillstånd (för muslimer) eller de förväntade fasorna som var att vänta på Domens dag. Dessa utvalda intensiva muntliga framföranden kombinerades ofta med bilder - stilla eller rörliga - med syfte att frammana en känslomässig respons hos publiken. Bilderna kunde till exempel visa människor i smärta eller andra former av mänskligt lidande, vilket hängde ihop med att dessa 'påminnelser' ofta försökte influera publiken till att utveckla solidaritetskänslor med den föreställda gemenskapen 'muslimer' samt uppmana till aktioner mot dem som framställdes som förande krig mot islam. En del av materialet innehöll uppmaningar till att delta i eller stötta militant jihad.

I detta material var mänskliga röster kombinerade med andra kommunikationssätt, främst stilla och rörliga bilder samt musik. De var alltså i hög grad redigerade eller bearbetade till form och innehåll, vilket är betydelsefullt för hur den bredare kommunikativa kontext i vilken rösterna var placerade. I dessa 'påminnelser' var medvetenheten om kommunikationssätt och estetik mer närvarande än i de videor med Shaykh Nazim som diskuterats ovan. Med specifikt fokus på röster i detta material är det relevant att notera att den första svenskspråkiga jihadistiska video som uppmanade publiken att ansluta sig till jihadistiska krigare i Syrien blev offentliggjord under den aktuella perioden. Gruppen som syntes i videon täckte över deras ansikten, men talaren avslöjade ändå något mycket personligt: han talade med en distinkt göteborgsdialekt. En lyssnare som är väl bevandrad i dialekter (eller sociolekter) i Göteborgs socialt och ekonomiskt mindre välmående områden skulle säkert kunna precisera talaren med viss geografisk precision. Att kunna identifiera sociolektala eller dialektala egenskaper hos en talare, exempelvis igenkänning av någon 'från kvarteret' eller talande en form av 'gatans språk', kan potentiellt 'röra' vissa lyssnare 
mer än andra. Vad som för en lyssnare kan uppfattas som 'skräp' eller 'oljud' kan för en annan lyssnare signalera 'hemma' eller 'någon som jag'. Detta kan jämföras med Weiners ovannämnda studie av dispyter rörande religiösa ljud i offentliga miljöer. Det kan även jämföras med musikgenrer som för den invigde direkt kan vara njutnings- och meningsfull, men för ett otränat öra upplevs som odifferentierat oljud. Det kan dessutom noteras att organiserade kriminella miljöer - inklusive jihadistiska grupper - ofta har sina egna normer, värden och lojaliteter som går på tvärs med majoritetskulturen (Truong 2018), vilka även kan uttryckas auditivt.

Vidare är det $\mathrm{i}$ jihad-orienterade diskurser och praktiker inte ovanligt att möta icke-lingvistiska, emotionellt kodade uttryck. Särskilt gråt kan nämnas som ett återkommande uttryck (Hegghammer 2017, 185f). Detta adderade ytterligare en ljudmässig dimension till rösterna jag arbetade med i detta projekt; de gav uttryck för känslor som kunde uppfattas som ilska och passion, men även smärta och lidande, vilket exempelvis uttrycktes genom gråt. Liksom dia- eller sociolekt, samt talarens föreställda andliga status i fallet med en sufishaykh, är detta en dimension av muntlighet som inte enkelt låter sig uttryckas eller fångas genom transkription. Ändå är det en integrerad och potentiellt viktig faktor i en lyssnares sinnligt upplevda interaktion med en ljudinspelning eller ett live-upplevt tal.

Mitt arbete med extremistiska budskap bidrog således till att öka mitt analytiska intresse för predikan och predikanter, men även mediering i bredare bemärkelse. Inte enbart med fokus på extremistiska ideologier, utan i ett bredare idémässigt och religiöst spektrum där uppmärksamhet kan ges till de komplexa kommunikativa processer som olika former av predikan kan innebära i dagens mångfacetterade medielandskap.

\section{Utvalda minoritetsröster och organiska röster}

Därmed har den kronologiska framställningen av tre lyssningsfaser nått fram till min pågående forskning. Sedan 2016 och framåt har jag mer avgränsat arbetat med olika typer av material relaterat till muslimsk predikan. Materialet inkluderar flera genrer och medieformer som har sina respektive produktionssätt och historier. En distinkt medieform jag undersökt är muslimska utgåvor av det svenska radioprogrammet Morgonandakten i P1, vilket har sänts sedan 1930 och därmed är det näst äldsta ännu existerande radioprogrammet i Sverige (det äldsta är Gudstjänsten på söndagar). Denna predikoform är professionellt producerad åt public service. Talarna i programmet är inbjudna som representanter för en specifik religion: kristendom, judendom eller islam (övriga religiösa identiteter ges inte utrymme inom programmet). I över 70 år var programmet exklusivt ägnat kristna talare, men år 2004 började även judiska och muslimska talare ges utrymme. Talarna förväntas (re)citera ett skriftställe ur Bibeln eller Koranen, följt av personliga reflektioner och berättelser utifrån detta skriftställe angående en viss religiös tematik. Programmet uppskattas ha omkring 60000 lyssnare. I den här kontexten behöver de muslimska rösterna höras som minoritetsröster vilka är individuellt inbjudna av programmets producenter. Dock ska noteras att de inbjudna talarna i regel inte har framstående religiösa positioner inom mus- 
limska församlingar eller fungerar som predikanter i moskéer. Istället är det programmets producenter som väljer ut och bjuder in möjliga passande talare, för att därefter redigera deras bidrag så att de lämpar sig till programmets relativt strikta form.

I en första artikel som byggde på detta material (Stjernholm 2019a) var fokus på att undersöka de huvudsakliga diskurserna som samlat sett framstod som dominerande i de muslimska morgonandakttalarnas program. Samtidigt noterades även aspekter av hur programmet ritualiseras till att bli ett islamiskt religiöst sammanhang, exempelvis genom recitation av Koranen på arabiska, inkluderande av fromma fraser och uttryck, eller att regelmässigt avsluta programmet med en islamiskt färgad åkallan $\left(d u^{\prime} a\right)$. I en andra artikel där fokus var riktat specifikt på sufi-orienterade budskap (Stjernholm 2019b), diskuterades även att denna mediegenres specifika auditiva form, där personlig reflektion och eftertanke uttrycks genom att en ensam (och därmed oemotsagd) röst, varvad med korta musikstycken, i sig själv passar vissa budskap bättre än andra. Den etablerade taleformen ger utrymme för individuella talare att auditivt skapa en slags intimitet med lyssnaren. Olika talare använder sin röst på olika sätt; det finns en möjlighet som vissa talare använder att tala lågt, nästan viskande, i delar av en morgonandakt - något som skulle vara omöjligt i många andra radioprogram som exempelvis kan bestå av intervjuer, debatter eller nyhetsrapportering. I artikeln noterades därmed att potentialen för att uttrycka intimitet och stilla personlig eftertanke - både diskursivt och auditivt - kan vara en gynnsam mediegenre för just sufi-orienterade budskap, där teman som inre upplevelser, känslor, innerlighet och kärlek ofta framhävs.

En annan stor del av materialet som undersöks i denna pågående fas av lyssnande består av ljud- och videoinspelningar där mer fristående muslimska predikanter framför sina budskap muntligt i exempelvis moskéer, privata hem och möteslokaler. I en artikel (Stjernholm 2019c) argumenterar jag för att begreppet 'DIY-predikan' är användbart för att analysera en viss typ av predikanters arbete med att på egen hand skapa och succesivt utveckla sina egna mediekanaler, samarbeten och produkter för att nå ut med sina budskap. ${ }^{4}$ Dessa predikanter skulle kunna ses som 'organiska röster', eller åtminstone som individer vilka försöker handa och tala på sätt som är organiska i relation till en del av befolkningen som i ett skandinaviskt hegemoniskt sammanhang ofta konstrueras som den diskursivt Andre. ${ }^{5}$ Att tala till en anonym 60000 huvuden stark publik genom en public service-kanal, att tilltala en publik av unga muslimer i en specifik muslimsk miljös moskélokal, eller att tala via medieformat som YouTube, Facebook och podcaster, kan kräva olika typer av röster. Dessa skillnader kan höras och analyseras. Ett sätt som jag nyligen närmat mig 'organiska' svenskspråkiga predikanters mediering av sina budskap är genom att rikta fokus på deras medvetna användande av det korta videoformat jag ovan benämnt 'påminnelser' (Stjernholm 2020). I denna artikel analyserades dels en serie korta videor (titeln för

${ }^{4}$ DIY är en förkortning av do it yourself, vilket blivit ett motto för alternativa kulturskapare inom många olika verksamhetsfält åtminstone sedan punken och framåt.

5 Mitt bruk av termen 'organisk' är inspirerat av Antonio Gramscis tänkande om "organiska intellektuella" och deras relation till en viss del av befolkningen (Gramsci 1971, 418; se även Grelle 2017, 60). 
serien var "90 sekunder") med igenkännbar form och tematik som producerats specifikt för och distribuerats via Facebook, dels en särskilt känslointensiv del av en längre föreläsning som klippts ut och kombinerats med musik och bilder.

I bägge dessa fall spelade respektive predikants röst och dess olika aspekter - härunder intonation, emfas, rytm och rim - en viktig roll. Centralt i analysen är det korta formatet: hur försöker predikanten på kort tid fånga publikens uppmärksamhet i flödet av samtidig information i sociala medier och 'röra' lyssnaren i en from riktning? Här spelar rösten på multimodalt vis samman med orden, bilderna och ljuden. Predikanten bakom serien "90 sekunder" syns i bild, ser rakt på tittaren och gestikulerar framför en digitalt arrangerad bakgrund som relaterar till det tema han talar om, exempelvis att sortera bort dåliga vänner för att hålla sig på den raka vägen, att lära sina barn att recitera suror ur Koranen, eller att vara ständigt medveten om den kommande Domens dag där alla ens handlingar kommer att vägas och bedömas. Dessa budskap framförs av predikanten med en snabbtungad, energisk och i viss grad exklamatorisk röst, dock utan de högre känslolägen som kan känneteckna längre utläggningar av ett ämne. Rösten är avvägd för att fånga uppmärksamheten, förmedla att budskapet är angeläget och viktigt, och därmed aktivera fromma normer och värderingar - men samtidigt utan att kräva allt för mycket av lyssnaren som scrollar igenom sitt Facebook-flöde. I påminnelse-video nummer två hörs en annan predikant, i ett redan uppskruvat känslo- och tonläge och med starkt rytmiskt tal, berätta om när profeten Muhammad ber den svarte frigivne slaven Bilal kalla till bön från taket av Ka 'ba i Mecka efter att de har återtagit makten över staden. Predikanten använder berättelsen för att kraftfullt fördöma nutida rasism och fördomar mot andra på grund av deras kulturella bakgrund - också muslimer emellan. Rösten samspelar med en musikslinga och en serie rörliga bilder, bland annat den scen ur filmen The Message (1976) som korresponderar med berättelsen. Bägge exemplen visar hur predikantens röst kan användas på distinkta vis som anpassas till ett visst sammanhang. Samtidigt interagerar rösten med de övriga samtidigt använda kommunikationssätten. Analyser av detta samspel mellan kommunikationssätt, samt hur sinnena aktiveras i processen, är även det ett fält som förtjänar mer religionsvetenskaplig uppmärksamhet.

\section{Avslutande ord}

Det finns fler aspekter som rör ljudet av religiositet och religiösa röster än de jag har diskuterat här. Jag har önskat framhäva några möjliga sätt att tänka kring hur valet av ljud i allmänhet, och röster i synnerhet, som vårt analysmaterial formar ramarna för och utförandet av vår analys. Genom de olika faserna av analytiskt lyssnande som jag har presenterat, har aspekter av muntlig kommunikation som inte begränsas till att förmedla diskursiva budskap succesivt kommit att bli allt viktigare i mitt arbete. Mänskligt tal är inte enbart text som framförs med munnen; snarare har ljudet av och lyssnandet till mänskliga röster meningsskapande potential i sig självt. Att rikta ana- 
lytiskt fokus på auditiva dimensioner av tal innebär att försöka avtäcka dessa meningsbärande aspekter som samverkar med orden. Ett sådant projekt adderar till, snarare än ersätter eller utmanar, tolkning och analys av språkliga uttryck.

Om vi väljer att exklusivt fokusera vår analys på de textuella aspekterna av tal (vilket i många fall är helt adekvat och fruktbart) bör vi vara medvetna om att vi etablerar en begränsning av vår analys genom att inte engagera oss i en ytterligare, potentiellt meningsbärande, del av materialet. Eftersom mänskligt tal består av mer än ord behöver detta 'mer' erkännas och - i de fall då det är adekvat och fruktbart - arbetas med. Vidare kan vi observera olika kulturellt formade lyssningspraktiker: våra analyser tillförs ett djup genom att vi lär oss förstå de semiotiska ideologier som präglar det specifika empiriska fält vi intresserar oss för. Alternativet är att vi mer eller mindre omedvetet utgår ifrån vår egen föredragna eller habituerade lyssningspraktik som om den vore naturlig eller alltid bäst lämpad för varje lyssningstillfälle. Genom att öva oss i att lyssna mer uppmärksamt kan vi öka vår förståelse för hur religiös kommunikation och praktik påverkar människors liv.

\section{LITTERATUR}

Abun-Nasr, Jamil M.

2007 Muslim Communities of Grace: The Sufi Brotherhoods in Islamic Religious Life, London: Hurst \& Company.

Atay, Tayfun

2012 A Muslim Mystic Community in Britain: Meaning in the West and for the West, Bremen: Europäischer Hochschulverlag.

Bandak, Andreas

2014 “Making 'Sound' Analysis: From Raw Moments to Attuned Perspectives”, in: Daniella Kuzmanovic \& Andreas Bandak, eds., Qualitative Analysis in the Making, New York: Routledge, 176-191.

Bull, Michael, and Les Back, eds.

2016 The Auditory Culture Reader, 2nd ed. London and New York: Bloomsbury.

Damrel, David

2006 "Aspects of the Naqshbandi-Haqqani Order in America", in: Jamal Malik \& John R Hinnells, eds., Sufism in the West, Abingdon: Routledge, 115-126.

Engelke, Matthew

2007 A Problem of Presence: Beyond Scripture in an African Church, Berkeley and Los Angeles: University of California Press.

Geaves, Ron

2000 The Sufis of Britain: An Exploration of Muslim Identity, Cardiff: Cardiff Academic Press.

Gramsci, Antonio

1971 Selections from the Prison Notebooks, redigeret og oversat af Quintin Hoare \& Geoffrey Nowell Smith, New York: International Publishers.

Grelle, Bruce

2017 Antonio Gramsci and the Question of Religion: Ideology, Ethics, and Hegemony, London and New York: Routledge. https://doi.org/10.4324/9781315640884

Hackett, Rosalind I.J.

2011 "Auditory Materials", in: Michael Stausberg \& Steven Engler, eds., The Routledge Handbook of Research Methods in the Study of Religion, London and New York: Routledge, 447-458.

2017 "Sound", in: Michael Stausberg \& Steven Engler, eds., The Oxford Handbook of the Study of 
Religion2 (online), Oxford: Oxford University Press.

https://doi.org/10.1093/oxfordhb/9780198729570.013.22

Hegghammer, Thomas

2017 "Non-Military Practices in Jihadi Groups", in: Thomas Hegghammer, ed., Jihadi Culture, Cambridge: Cambridge University Press, 171-201. https://doi.org/10.1017/9781139086141.009

Hirschkind, Charles

2006 The Ethical Soundscape: Cassette Sermons and Islamic Counterpublics, New York: Columbia University Press.

2012 "Experiments in Devotion Online: The YouTube Khuṭba", International Journal of Middle East Studies 44/1, 5-21. https://doi.org/10.1017/S002074381100122X

Ihde, Don

2007 Listening and Voice: Phenomenologies of Sound, 2. ed. State University of New York Press.

Jacobsen, Brian Arly, Drude Daverkosen, og Luna Skjoldann Larsen

2019 "De stille moskéer og kirkeklokkernes genklang", Tidsskrift for Islamforskning 13/2, 59-76. https://doi.org/10.7146/tifo.v13i2.117769

Keane, Webb

2008 "The Evidence of the Senses and the Materiality of Religion", Journal of the Royal Anthropological Institute 14/1, 110-127. https://doi.org/10.1111/j.1467-9655.2008.00496.x

Kress, Gunther

2010 Multimodality: A Social Semiotic Approach to Contemporary Communication, London and New York: Routledge. https://doi.org/10.4324/9780203970034

Meyer, Birgit

2011 "Mediation and Immediacy: Sensational Forms, Semiotic Ideologies and the Question of the Medium", Social Anthropology/Anthropologie Sociale 19/1, 23-39. https://doi.org/10.1111/j.14698676.2010.00137.x

Nielsen, Jørgen S, Mustafa Draper, and Galina Yemelianova

2006 "Transnational Sufism: The Haqqaniyya", in: Jamal Malik \& John R. Hinnells, eds., Sufism in the West, Abingdon: Routledge, 103-114.

Schmidt, Leigh Eric

2000 Hearing Things: Religion, Illusion, and the American Enlightenment, Cambridge, Mass.: Harvard University Press.

Schulz, Dorothea

2012a “Dis/Embodying Authority: Female Radio 'Preachers' and the Ambivalences of Mass-Mediated Speech in Mali", International Journal of Middle East Studies 44/1, 23-43. https://doi.org/10.1017/S0020743811001231

2012b Muslims and New Media in West Africa: Pathways to God. Bloomington Indianapolis: Indiana University Press.

2012c “Reconsidering Muslim Authority: Female 'Preachers' and the Ambiguities of Radio-Mediated Sermonizing in Mali", in: Lucas Bessire \& Daniel Fisher, eds., Radio Fields: Anthropology and Wireless Sound in the 21st Century, New York \& London: New York University Press, 108-123. https://doi.org/10.18574/nyu/9780814771679.003.0005

2015 "Mediating Authority: Media Technologies and the Generation of Charismatic Appeal in Southern Mali", Culture and Religion 16/2, 125-145.

Sterne, Jonathan

2008 "Enemy Voice", Social Text 26/3 (96), 79-100. https://doi.org/10.1215/01642472-2008-005

Sterne, Jonathan, ed.

2012 The Sound Studies Reader, London and New York: Routledge. https://doi.org/10.4324/9780203723647

Stjernholm, Simon

2011 "Lovers of Muhammad: A Study of Naqshbandi-Haqqani Sufis in the Twenty-First Century", 
Centre for Theology and Religious Studies, Lund University.

2014 "What Is the Naqshbandi-Haqqani Tariqa? Notes on Developments and a Critique of Typologies", in: Ron Geaves and Theodore Gabriel, eds., Sufism in Britain, London: Bloomsbury Academic, 197-211.

2015 "The Centre of the Universe: Shaykh Nazim and His Murids in Lefke, Cyprus", Journal of Muslims in Europe 4/1, 38-57. https://doi.org/10.1163/22117954-12341294

2019a "Muslim Religious Oratory on Swedish Public Service Radio", Journal of Contemporary Religion 34/1, 57-73. https://doi.org/10.1080/13537903.2019.1585103

2019b "Sounding Sufi: Sufi-Oriented Messages on Swedish Public Service Radio," in: Francesco Piraino \& Mark Sedgwick, eds., Global Sufism: Boundaries, Structures, and Politics, London: Hurst \& Co., 193-208.

2019c “DIY Preaching and Muslim Religious Authority." Journal of Muslims in Europe 8/2, 197-215. https://doi.org/10.1163/22117954-12341393

2020 "Brief Reminders: Muslim Preachers, Mediation, and Time", in: Simon Stjernholm and Elisabeth Özdalga, eds., Muslim Preaching in the Middle East and Beyond: Historical and Contemporary Case Studies, Edinburgh: Edinburgh University Press.

Truong, Fabien

2018 Radicalized Loyalties: Becoming Muslim in the West, Cambridge: Polity Press.

Weiner, Isaac

2011 "Sound", Material Religion 7/1, 108-115. https://doi.org/10.2752/175183411X12968355482259

2014 Religion Out Loud: Religious Sound, Public Space, and American Pluralism, New York \& London: New York University Press.

Weismann, Itzchak

2007 The Naqshbandiyya: Orthodoxy and Activism in a Worldwide Sufi Tradition, Abingdon: Routledge. https://doi.org/10.4324/9780203947432

Simon Stjernholm, lektor, ph.d. Institut for Tværkulturelle og Regionale Studier, Københavns Universitet 